ISSN 0974-3618 (Print) 0974-360X (Online) www.rjptonline.org
ARJPT

RESEARCH ARTICLE

\title{
The Effect of Bifidobacterium Probiotic on Heat Shock Protein-70 Expression and Osteoclast Number during Orthodontic Tooth Movement in Rats (Rattus novergicus)
}

\author{
Ari Triwardhani*, Intan Oktaviona ${ }^{1}$, Ida Bagus Narmada ${ }^{1}$, Alexander Patera Nugraha ${ }^{1}$, \\ Wibi Riawan ${ }^{2}$ \\ ${ }^{1}$ Orthodontics Department, Faculty of Dental Medicine, Airlangga University, Surabaya, Indonesia. \\ ${ }^{2}$ Biomolecular Biochemistry Department, Faculty of Medicine, Brawijaya University, Malang, Indonesia. \\ *Corresponding Author E-mail: ari-t@fkg.unair.ac.id
}

\begin{abstract}
:
Heat shock protein (HSP)-70 expressed in the fibroblast of periodontal ligament after orthodontic tooth movement (OTM) was applied. Bifidobacterium probiotics regulate the number of osteoclasts through controlling the inflammation via Nuclear Factor Kappa Beta (NFKB) and increased cytoprotection by HSP induction. This study aimed to examine the effect of Bifidobacterium probiotic on HSP-70 expression and osteoclast number during OTM in the compression side of Wistar rats (Rattus novergicus). This research was a true experimental study which used post-test only group design. 42-healthy-Wistar rats $(R$. novergicus $)$ were blind randomly divided into 6 groups; K1: OTM for 3 days; K2: OTM for 7 days; K3: OTM for 14 days; KP1: OTM and administration of Bifidobacterium probiotic for 3 days; KP2: OTM and administration of Bifidobacterium probiotic for 7 days; KP3: OTM and administration of Bifidobacterium probiotic for 14 days. OTM model was made by installed closed-coil spring with $10 \mathrm{~g} / \mathrm{mm}^{2}$ force. Bifidobacterium probiotic was orally administered with $10 \mathrm{~mL} /$ day by means of oral gavage at $1.5 \times 10^{8} \mathrm{CFU} / \mathrm{mL}$ dose every day. Immunohistochemical analyses were performed in all study groups. One-way ANOVA and LSD test $(\mathrm{p}<0.05)$ were performed to compare between groups. The highest HSP-70 expression was discovered in K3 control group and the greatest osteoclast number was found in KP1 control group. The lowest HSP-70 expression and osteoclast number were found in KP3 group with significant between groups. Bifidobacterium probiotic decreased the expression of HSP-70 and osteoclast number during the orthodontic tooth movement in 14 days in the compression side.
\end{abstract}

KEYWORDS: Bifidobacterium, Food Nutrition Improvement, Heat Shock Protein-70, Medicine, Osteoclast.

\section{INTRODUCTION:}

Malocclusion is one problem in dentistry that has effect on oral condition and is able to cause problems in mastication, articulation, and arch development. ${ }^{1}$ The prevalence of malocclusion in Indonesia remains high, at approximately $80 \%$ of the population. ${ }^{2}$ Orthodontic treatment was recommended for patient with malocclusion. ${ }^{3}$ The existence of malocclusion numerous oral health issues as it disturbs the functional needs as well as jeopardizes a person's dentofacial esthetics, speech, mandibular function and psychological state. ${ }^{4}$
The movement of tooth by deposition and resorption of alveolar bone, also called as remodeling, is resulted from the application of orthodontic force on the structure of the tooth. Bone remodeling is an essential process for tooth movement during orthodontic treatment. ${ }^{5}$ The intercourse that takes place between bone component cells which are osteoclast, osteoblast and osteocyte strictly influences bone remodeling. ${ }^{6}$ Osteoclast bone resorption antecedes osteoblast bone formation during the bone remodeling course. ${ }^{7}$ Heat Shock Protein (HSP)70 was expressed in the fibroblast of periodontal ligament when orthodontic force was applied. HSP are molecular guardian or protein protector which maintain the dynamic balance of protein folding and interactions as well as equilibrium within cell, and hinder the aggregation of protein. ${ }^{8,9}$ Since dysregulated 
inflammation damages tissue and causes root resorption and periodontal disease, the inflammation that happens during orthodontic tooth movement (OTM) shall be under strict control. ${ }^{10}$ However, some tissue damage is unavoidable during OTM, and is actually beneficial, because it evokes inflammation that lead to activation of Nuclear factor of activated T-cells (NFATC) and Sclerostin (SOST) in the osteoclast. ${ }^{11}$ Previous epidemiological study showed that all patients with inclusive orthodontic treatment suffered from root shortening, while a small percentage of the patients $(3 \%)$ suffered from severe root resorption. Various constituents determine the severity of root resorption, such as the applied force magnitude, orthodontic appliance type, tooth movement type, force application time, local and systemic disease, the person's age, hereditary factors affiliated to root anomaly, trauma and ethnicity. ${ }^{12}$ fibroblast growth factor (FGF) and vascular endothelial growth factor (VEGF) play important role as growth factor to main the homeostasis of bone remodeling during OTM to minimize the side effect of orthodontic treatment. ${ }^{13}$

Probiotics are considered as functional food which is defined as living microorganisms which will provide the host with health benefits if administered in appropriate amount. ${ }^{14,15} \mathrm{In}$ regards to food, this definition is modifiable by highlighting that these favorable effects come from the microorganisms "when consumed in appropriate amount as part of food". ${ }^{16}$ Probiotics are commonly claimed to decrease the potentiallypathogenic gastrointestinal microorganisms, to improve bowel regularity, to lessen flatulence and bloating, to defend DNA, to keep protein and lipid from oxidative damage, as well as to maintain individual intestinal microbiota in those consuming antibiotics. ${ }^{17}$ Probiotic is likely able to change oral microbiota and it is currently under research to either prevent or treat oral cavity diseases, such as dental caries and periodontal diseases, that are related with a change in microbial composition and biofilm activity, and the host's resulting reaction. The most common investigations are aimed to Lactobacillus, Streptococcus and Bifidobacterium strains as probiotics. ${ }^{18}$ Probiotic is generally immersed in the modulation of pathogenic bacterial adhesion to the intestinal epithelium and its reputation has received growing attention due to their performance in systemic and oral health promotion. Several investigations have found it to have some effects on inflammation, including alveolar bone resorption. ${ }^{19}$ Oral Supplementation with probiotic affected osteoclasts amount adjoining to the root during orthodontic movement in rats. ${ }^{20}$ The beneficial effects of some probiotics on the gut mucosa may be due to a combination of decreased inflammation via blockade of nuclear factor-kappa $\beta$ (NFK $\beta$ ) activity and increased cytoprotection through HSP induction.
This examination aimed to figure out the effect of Bifidobacterium on HSP-70 expression and osteoclast number during OTM in the compression side of Wistar rats (Rattus novergicus).

\section{MATERIAL AND METHODS:} Ethical Clearance and Study Design:

This research was an experimental and observational analytic research which used post-test only control group design. The samples were selected using simple random sampling method. This study's animal experimental protocol had been recognized by the Animal Experiments Ethics Committee of Airlangga University in Surabaya (acceptance number: 624/HRECC.FODM/X/2019).

\section{Orthodontic Tooth Movement Animal Model:}

42, healthy, 16-20-weeks of age, male, Wistar strain mice of 200-250g weight were selected for the animal study. All of the rats were placed in the animal center of Veterinary Medicine, Universitas Airlangga, Surabaya. It was in compliance with in vivo experiments guidelines to lighten the animals pain. All of the rats were placed distinctively in a poly carbonate cage for one week on a 12 hours light/dark cycle at a regular temperature of $25^{\circ} \mathrm{C}$ and humidity of $50 \%$ for the acclimatization to negate their distinctive origins. The mice were consumed a standard pellet diet with faucet and regularly monitored for food usage and feces attributes. ${ }^{5}$ The samples were blind randomly divided into 6 groups; K1: OTM for 3 days; K2: OTM for 7 days; K3: OTM for 14 days; KP1: OTM and intake of Bifidobacterium probiotic for 3 days; KP2: OTM and administration of Bifidobacterium probiotic for 7 days; KP3: OTM and administration of Bifidobacterium probiotic for 14 days.

The orthodontic tooth movement was performed by 6 $\mathrm{mm}$ long NiTi coil spring (Ortho technology, China) which located among the first incisor and first maxillary molars and fixed by utilizing 0.07 stainless steel ligature wire over the maxillary incisor with $10 \mathrm{~g} / \mathrm{mm}^{2}$ strength calculated by a tension gauge (Figure 1). Rodent anesthesia $(60 \mathrm{mg} / \mathrm{body}$ weight of ketamine and xylazine $3 \mathrm{mg} /$ weight) was used on the animals. The rats' premaxilla was anatomized and drowned in $10 \%$ concentration of formalin for four days. One month of premaxilla decalcification with ethylenediaminetetra acetic acid (EDTA) was then conducted. ${ }^{1-3,8}$

\section{Bifidobacterium Probiotic preparation:}

Bifidobacterium probiotic was made from Food and Nutrition Center in Gadjah Mada University, Yogyakarta, Indonesia. The strain was Bifidobacterium bifidum BRL 130 with certificate confirmation number PSPG/0309/IV/19. Animals of probiotic group were orally administered with $10 \mathrm{~mL} /$ day of Bifidobacterium 
in drinking water at $1.5 \times 10^{8} \mathrm{CFU} / \mathrm{mL}$ dose every day. HSP-70 expression and Osteoclast staining:

The Immunohistochemistry staining was done at Molecular Biochemistry Department, Faculty of Medicine, Brawijaya University, Malang, Indonesia. The samples were inspected by immunohistochemical staining by utilizing a 3.3'-diaminobenzidine stain kit (Pierce $^{\mathrm{TM}}$ DAB Substrate Paint Kit 34002, Thermofisher ${ }^{\mathrm{TM}}$, Waltham, Massachusetts, US) and monoclonal antibodies (Santa Cruz Biotechnology US) anti-HSP 70 (no cat. Sc-24) in the alveolar bone was ready for microscopy elucidation. Osteoclast was examined by means of its morphology which is multinucleated giant cells near the bone resorption area by mean of hematoxylin eosin (HE) staining The inspection was performed by 2 observers in 5 different sight points and used Nikon H600L light microscope (Japan) at 400x magnification with a 300 megapixels Fi2 DS digital camera and image processing software Nikon Image System (Nikon, Japan).

\section{Statistical Analysis:}

The information material was analysed using Statistical Package for Social Science (SPSS) 20.0 software (for Windows, SPSS, Chicago, USA). Descriptive statistics were presented as means \pm Standard Deviation (SD). ANOVA and LSD $(p<0.05)$ were performed to examine the HSP-70 expression and osteoclast number between groups.
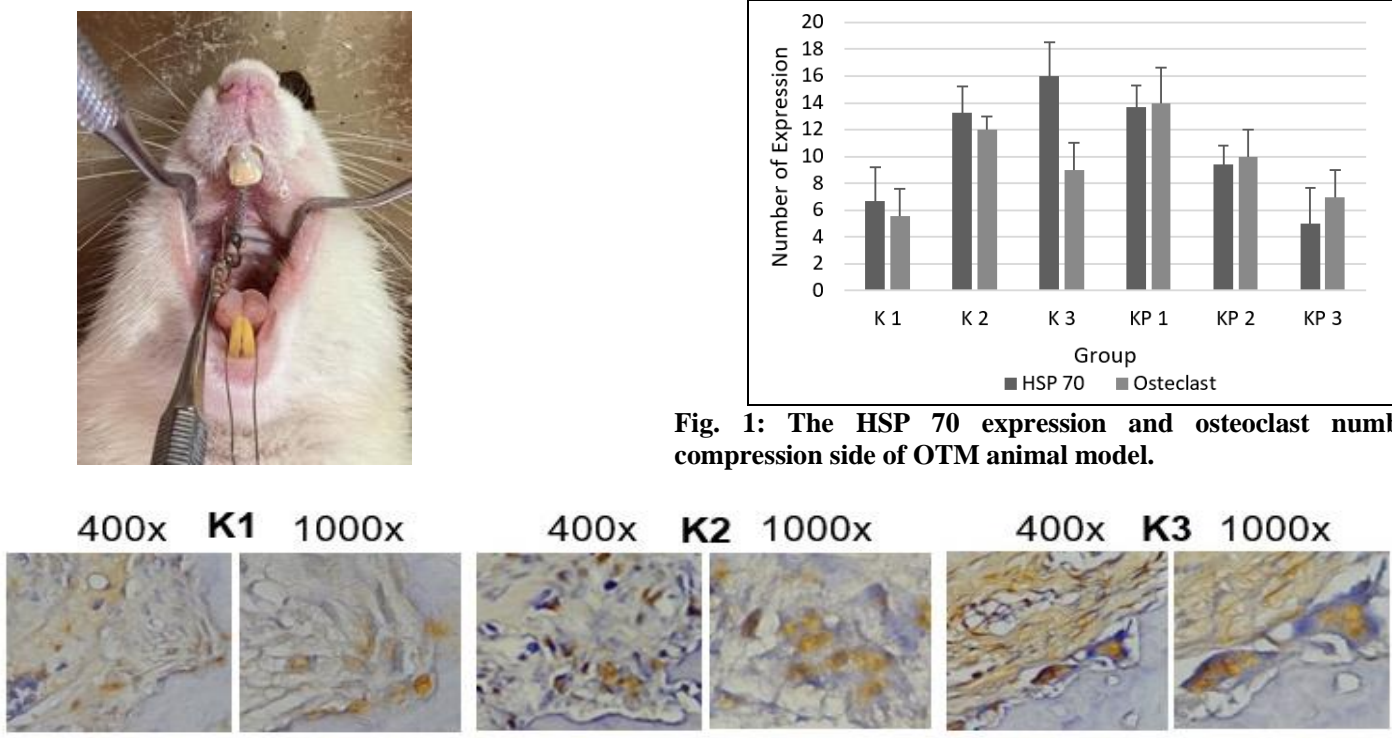

HSP-70
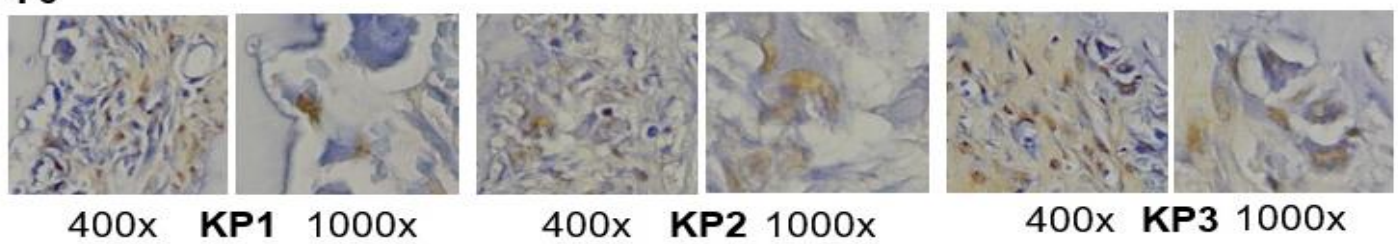

Fig. 2: Positive expressions of HSP-70 were found in the fibroblast in the periodontal ligament during OTM (compression side) with 400x 
and 1000x magnification accordingly observed by means of light microscope.

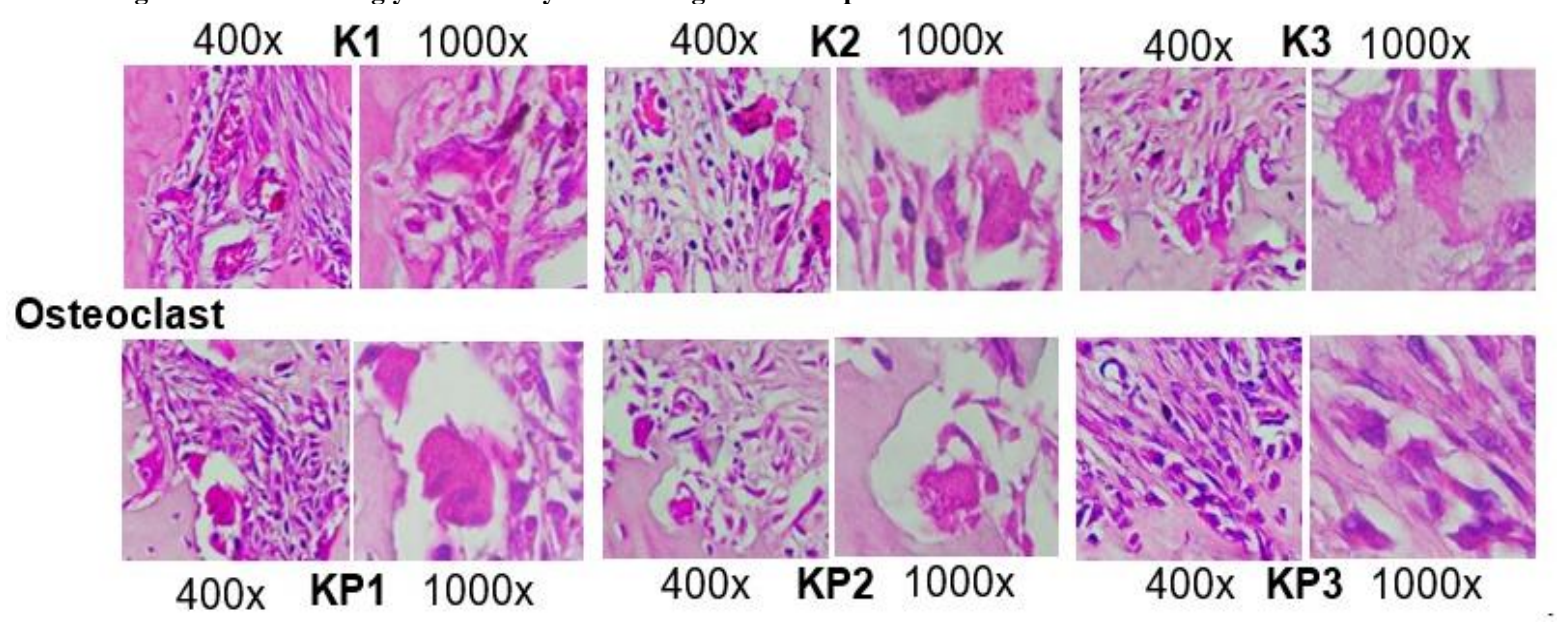

Fig. 3: The multinucleated giant cell surrounded by bone resorption was osteoclast which is found in the alveolar bone during OTM (compression side) with 400x and 1000x magnification accordingly observed by means of light microscope.

Bone remodeling is an active action needed for bone stability and organized by producing bone by osteoblast, resorbing bone by osteoclast and their molecular signal. ${ }^{21}$ HSPs molecules play an important role in facilitation folding of proteins, they have cytoprotection role in cells exposed to stress, which is considered as hazard signaling biomarkers and implicated in proinflammatory and anti-inflammatory responses..$^{22}$ In this research, we have found that, in the compression side, there was a heightened expression of HSP 70 in the control groups compared to treatment groups. OTM was performed using $10 \mathrm{~g} / \mathrm{mm}^{2}$ orthodontic force via application of Nickel Titanium coil spring located among the first incisor and first maxillary molars. Previous study mentioned that $10 \mathrm{~g}$ of a light force administration of OTM can produce incomparably bigger tooth movement with much less root resorption..$^{5,8,23}$ Oxidative stress in PDL might be induced due to this force, which activates Heat Shock Factor-1 (HSF-1) and later increases HSP-70 inside cytoplasm. The rise expression of HSP-70 expression in the cell trigger extracellular HSP-70 production. $^{8,23}$ In other study, section of early pulpal reaction to trauma was formed by the expression of HSP-70. HSP-70 mRNA expense in dental pulp through orthodontic tooth movement was discovered become bigger on day 3,7,14 and 28 after being inserted with elastic rubber blocks. This indicates that orthodontic tooth movement leads to degenerative alteration and apoptosis in pulp cells, whilst pulp homeostasis is preserved at the genetic grade. ${ }^{24}$ There was a considerable reduction in HSP-70 expression in the Bifidobacterium probiotic groups contrasted with control groups in the compression side, which validated that Bifidobacterium could influence the HSP of periodontal tissue applied with orthodontic force. The result is in accordance with previous study with Lactobacilus casei probiotic on days 7-21 showed the effect of probiotic can be seen in day 7 and decrease in HSP 70 expression. ${ }^{25} \mathrm{~A}$ daily intake of probiotic strains may help to recover or preserve diversity and stability of the host's oral biofilm as well as modulate immune responses ${ }^{26}$ Probiotics are able to adjust the immune reaction with decreasing the output of pro-inflammatory cytokines and raising the output of anti-inflammatory cytokines. ${ }^{27}$ Thus, we can assume that the intake of products that are enriched with probiotics could give a lot of advantages (for patients who suffer from osteoporosis in particular), however it may hinder orthodontic treatment. ${ }^{19}$ Osteoclast on day 7 in control group was higher than day 14 in control groups. The research outcome is parallel to previous study which argued that the tooth movement reached a maximal restrict on day 8 via coil spring disposition. The number of osteoclasts raised significantly in the compression side of the periodontal ligament with a maximal enhancement on day 8. Osteoclast in probiotic groups also decreased compared to control groups in this study. The result is in accordance with the preceding study which argued that the probiotic therapy for 12 days was able to reduce the number of osteoclasts in the periodontal tissues in the compression area of teeth with mechanic load in mice. ${ }^{2,24}$

\section{CONCLUSION:}

Based on the result of the molecular aspect can be concluded that Bifidobacterium probiotic has effect to decrease the expression of HSP-70 and osteoclast number during the orthodontic tooth movement in 14 days on compression side in Wistar Rats ( $R$. novergicus).

\section{ACKNOWLEDGEMENT:}

This study was funded by Penelitian Unggulan Fakultas 
(PUF) supported by Airlangga University with appointment number: 346/UN3/2020 The authors

express the sincerest gratitude to the authorities of

Faculty of Dental Medicine Airlangga University and

Faculty of Medicine, Brawijaya University, Malang, Indonesia for the assist.

\section{CONFLICT OF INTEREST:}

The authors declare no conflict of interest.

\section{REFERENCES:}

1. Hisham PBBM, Narmada IB, Alida A, Rahmawati D, Nugraha AP, Putranti NA. Effects of Vitamin D in Alveolar Bone Remodeling on Osteoblast Numbers and Bone Alkaline Phosphatase Expression in Pregnant Rats During Orthodontic Tooth Movement. J Orofac Sci 2019; 11: 79-83

2. Narmada IB, Husodo KRD, Ardani IGAW, Rahmawati D, Nugraha AP, Iskandar RPD. Effect of Vitamin D during Orthodontic Tooth Movement on Receptor Activator of Nuclear Factor Kappa-B Ligand Expression and Osteoclast Number in Pregnant Wistar Rat (Rattus novergicus). JKIMSU 2019; 8(1): 3842.

3. Nareswari RAAR, Narmada IB, Djaharu'ddin I, Rahmawati D, Putranti NAR, Nugraha AP. Effect of vitamin D administration on vascular endothelial growth factor expression and angiogenesis number in orthodontic tooth movement of pregnant Wistar rats. J Postgrad Med Inst 2019; 33(3): 182-8.

4. Sharmin S, Zakir H. Prevalence and factors related to malocclusion, normative and perceived orthodontic treatment need among children and adolescents in Bangladesh. Dental Press J. Orthod. 2019; 24( 3 ): 44.e1-44.e9.

5. Sitasari PI, Narmada IB, Hamid T, Triwardhani A, Nugraha AP, Rahmawati D. East Java green tea methanolic extract can enhance RUNX2 and Osterix expression during orthodontic tooth movement in vivo. J Pharm Pharmacogn Res 2020; 8(4): 290-298

6. Rezkita F, Wibawa KGP, Nugraha AP. Curcumin loaded Chitosan Nanoparticle for Accelerating the Post Extraction Wound Healing in Diabetes Mellitus Patient: A Review. Research J. Pharm. and Tech. 13(2): February 2020.1039

7. Nugraha AP, Rezkita F, Putra KG, Narmada IB, Ernawati DS, Rantam FA. Triad Tissue Engineering: Gingival Mesenchymal Stem Cells, Platelet Rich Fibrin and Hydroxyapatite Scaffold to ameliorate Relapse Post Orthodontic Treatment. Biochem. Cell. Arch. 2019; 19(2): 3689-3693.

8. Nugraha AP, Narmada IB, Sitasari PI, Inayati F, Wira R, Triwardhani A, et al. High mobility group box 1 and heat shock protein-70 expression post (-)-epigallocatechin-3-gallate in East Java green tea methanolic extract administration during orthodontic tooth movement in wistar rats. Pesqui Bras Odontopediatria Clín Integr. 2020; 20:e5347.

9. Susmi MS, Kumar RS, Sreelakshmi V, Menon SV, Mohan S, Suja ST, Sathianarayanan, Asha MAA. Computational approach for identification of Phytochemicals for targeting and optimizing the inhibitors of Heat shock proteins. Research J. Pharm. and Tech 2015; 8(9): 1199-1204.

10. Li Y, Jacox LA, Little SH, Ko CC. Orthodontic tooth movement: The biology and clinical implications. Kaohsiung J Med Sci. 2018 Apr; 34(4): 207-214.

11. Hermawan RW, Narmada IB, Djaharu'ddin I, Nugraha AP, Rahmawati D. The Influence of Epigallocatechin Gallate on the Nuclear Factor Associated T Cell-1 and Sclerostin Expression in Wistar Rats (Rattus novergicus) during the Orthodontic Tooth Movement. Research J. Pharm. and Tech. 2020; 13(4): 1730-1734.

12. Hikida T, Yamaguchi M, Shimizu M, Kikuta J, Yoshino T, Kasai K. Comparisons of orthodontic root resorption under heavy and jiggling reciprocating forces during experimental tooth movement in a rat model. Korean J Orthod. 2016; 46(4): 228-241.

13. Inayati F, Narmada IB, Ardani IGAW, Nugraha AP, Rahmawati D. Post Oral Administration of Epigallocatechin Gallate from Camelia sinensis Extract Enhances Vascular Endothelial Growth Factor and Fibroblast Growth Factor Expression during Orthodontic Tooth Movement in Wistar Rats. JKIMSU 2020; 9(1): 58-65.

14. Moorthy MK, Nayak BK, Nanda A. Antioxidant and antitumor activity of lactic bacteria isolated from natural beverage - Coconut toddy. Research J. Pharm. and Tech 2017; 10(12): 4317-4320.

15. Chauhan SB, Singh V, Chauhan R. Enteric coated Microbeads as a Potential Delivery System for improved probiotic effect of Lactobacillus rhamnosus GG. Research J. Pharm. and Tech. 2019; 12(12): 6049-6056.

16. Hossain MK, Nahar K, Shokryazdan P, Abdullah N, Hamid K, Jahromi MF. Probiotic Potential of Lactic Acid Bacteria Isolated from Cheese, Yogurt and Poultry Faeces. Research J. Pharm. and Tech. 2017; 10(9): 2991-2998.

17. Swathi KV. Probiotics -A Human Friendly Bacteria. Research J. Pharm. and Tech 2016; 9(8): 1260-1262.

18. Allaker RP, Stephen AS. Use of Probiotics and Oral Health. Curr Oral Health Rep. 2017;4(4): 309-318.

19. Foureaux RC, Messora MR, de Oliveira LF, Napimoga MH, Pereira AN, Ferreira MS, Pereira LJ. Effects of probiotic therapy on metabolic and inflammatory parameters of rats with ligatureinduced periodontitis associated with restraint stress. J Periodontol. 2014; 85(7): 975-83.

20. Pazzini CA, Pereira LJ, da Silva TA, Montalvany-Antonucci CC, Macari S, Marques LS, de Paiva SM. Probiotic consumption decreases the number of osteoclasts during orthodontic movement in mice. Archives of Oral Biology, $24 \mathrm{Feb} 2017,79: 30-34$

21. Xiao W, Wang Y, Pacios S, Li S, Graves DT. Cellular and Molecular Aspects of Bone Remodeling. Front Oral Biol. 2016; 18: 9-16

22. Mohammed ZI, Hassan AJ. Effect of Bee venom on gene expression of HSP70 and IL- $1 \beta$ in male rats induced by arthritis in comparison with Prednisolone drug. Research J. Pharm. and Tech. 2019; 12(11): 5269-5274.

23. Narmada IB, Rubianto M, Putra ST. The effect of low-level light therapy on orthodontic tooth movement rate, heat shock protein 70, and matrix metallopreteinase 8 expression: Animal study. Dent Res J (Isfahan). 2020; 17(1): 73-79.

24. Kaneko-Tanaka K, Kurokawa A, Mitsuhashi M, Fujita S, Goseki T, Yamaguchi M, Kasai K. Expression of Heat Shock Protein 70 in the Periodontal Ligament During Orth-odontic Tooth Movement. Int J Oral-M ed Sci 9 (2): 115-121, 2010.

25. Triwardhani A. Regulation Mechanism of Alveolar Bone Remodeling during Orthodontic Tooth Movement induced by Lactobacillus Casei. Disertation Airlangga University. 2016;58.

26. Park H. Effect of Salivary Streptococci mutans and Lactobacilli levels after uptake of the Probiotic for Clinical Trial. Research J. Pharm. and Tech. 2017; 10(9): 2984-2988.

27. Cheryomushkina IV, Korneeva OS. Innovative Biotechnology Probiotic Feed Additives $\mathrm{C}$ and Immunostimulatory Effects. Research J. Pharm. and Tech. 2017; 10(4): 1165-1167. 